\title{
Influence of iTax System on Service Delivery at the Kenya Revenue Authority
}

\author{
Samuel Otieno John \\ Department of Agricultural Economics and Natural Resource Management, Moi University, Kenya
}

\begin{abstract}
Tax system provides a convenient and efficient way of improving revenue collection and transparency in fiscal administration. This study aimed at determining the effect of the itax system on service delivery by the Kenya Revenue Authority in Eldoret Station. The study used a stratified random sampling technique to sample 37 Kenya Revenue Authority employees in Eldoret stations. The data were analyzed by use of descriptive statistics and regression techniques. The empirical results of the study showed that $i$ Tax stability was statistically significant with a (p-value $=0.003$ ), iTax security had a significant association with service delivery $(p$-value $=0.001$ ), and iTax technical skills also had a substantial relationship with service delivery with a (p-value =.066). The study concluded that iTax systems affect service delivery at KRA in Eldoret station due to a robust statistical association between the iTax systems and service delivery. The study recommended that the Kenya Revenue Authority should establish tight policy measures to curb the issues associated with iTax insecurity and finally employ staff with technical knowledge and skills on the iTax system.
\end{abstract}

Keywords: itax system, service delivery, revenue

\section{INTRODUCTION}

$\mathrm{G}$ obally, the tax environment has changed rapidly. The tax authorities are being challenged to maintain a modernized and responsive tax administration system. Tax agencies leverage the electronic tax filing (e-filing) system to achieve more excellent tax administrative and compliance efficiency (Van and James, 2010). Electronic filing is the modern way of tax authorities interacting with taxpayers. Tax practitioners do not see that the conversion to electronic filing offers much to them in terms of return on their investment, considering the cost of software and hardware needed to adopt the e-filing technology (Simiyu, 2013). Although many tax practitioners perceive that electronic filing is an essential and improved service, they do not view it as vital to gaining a competitive advantage (Veras and Preziosi, 2011). Electronic tax administration systems have gained prominence in SubSaharan Africa (SSA) in the 21st century. This has been spurred on by the need for improved efficiency and accountability in taxation systems and inherently adopting information technology (IT) tax-based systems (OECD, 2010). Population growth and demands for transparency in tax administration policy have further emphasized the need for better revenue collection systems and procedures in East African countries (Addision et al., 2014).

Electronic tax systems are designed to reduce the cost of tax administration, ensure ease of compliance, and provide for accuracy and equity in tax administration. This is in line with the canons of tax administration as explained by Adam Smith (Davidson, 2015), which are economy, convenience, certainty, and equity. Electronic tax systems bring taxation services closer to the taxpayer, thus enhancing revenue collection. They are essential in collecting revenue for governments which is in turn used to provide services to citizens. This is in line with the cost of service theory which states that revenue authority should levy based on the services rendered by the government (Azmi et al., 2016). It is therefore essential that revenue administrators widen the tax base to capture all taxpayers in the system. The need to consider the benefits received from taxes in tax policy formulation is underpinned in the benefits received theory. Proponents of this theory posit that taxpayers should pay taxes for only those goods or services they derive benefits from (Roger, 2010).

The East Africa region was not left behind; Uganda and Tanzania were early reformers of their revenue administration systems in the Eastern Africa Region (KRA, 2012). Muhangi (2012) notes that in Uganda, the Uganda Revenue Authority (URA) in 2005 developed an online tax system dubbed 'eTax.' Mugo (2013) further comments that the purpose of the online tax system was to enable efficiency in the tax administration process as well as reduce the taxpayer's expenses in tax compliance. In Tanzania, on the other hand, the electronic filing of VAT returns was introduced in October 2012, significantly reducing the time taken to file the tax returns. Additionally, in 2013 the Tanzania Revenue Authority (TRA) launched a Revenue Gateway System, an interface between the TRA and commercial banks enabling seamless payments of taxes.

The Kenya Revenue Authority introduced online filing through the iTax system that replaced the Integrated Tax Management Systems. The online filing of tax returns induced benefits that were not possible through the manual filing of the tax returns. These benefits include the element of convenience to the taxpayer, reduced costs on the revenue authority, and quality data on tax returns due to the elimination of data entry errors associated with the manual filing. In this Plan, KRA emphasized the importance of using technology to enhance tax compliance. This was seen to deal with tax evasion and fraud (KRA report, 2015). The iTax online system facilitates payment of all income taxes, VAT, and excise duty. The iTax system had started on a good note as far as increasing tax compliance is concerned. Currently, 
there are more than 1.6 million users of the system. This figure is expected to increase as more taxpayers sign up with the KRA stepping up its awareness drive. According to the current KRA, the 2017 report, the use of itax has enabled the collection of KES1.365 trillion in the 2016/2017 financial year. This is about a $55 \%$ increase in revenue collection compared to the dark ages during the manual filing of the tax return.

Despite the positive impacts associated with the itax system, KRA employees are encountering severe challenges related to this electronic system. These problems include limited network coverage, data integrity, tax insecurity, poor public itax knowledge, itax instability, among others. These havocs hinder KRA staffs from delivering quality service to taxpayers. They also mimic the realization of KRA's goal of enabling the government of Kenya to achieve revenue independence which would effectively eliminate its reliance on financing its budget deficit through loans. However, most of the studies (Korir et al., 2015; Kiring'a 2017 and Gitaru, 2017) have focused on the technical aspect of technology adoption of the itax system with limited focus on these effects of the itax system in Kenya. This study, therefore, seeks to fill this knowledge gap by examining the impact of iTax system on service delivery by Kenya Revenue Authority in Eldoret station.

\section{LITERATURE REVIEW}

\section{iTax Computer literacy level and service delivery}

The computer literacy level and accessibility to internet infrastructure directly impact the use of online tax returns (Auyat, 2013). The online tax services are often internet-based platforms, and basic knowledge of internet usage is required (Azmi \& Bee, 2011). In this context, the user must be able to self-navigate the web-based platform with minimal difficulties, if any, and use the self-help menus available on the website (Hussein et al., 2010). Naomi and Joel (2011) noted that half the sampled respondents in their study on adopting the ITMS system indicated that any online egovernment services need to be easy to use to enable even those with little internet experience to use the service effectively. In this context, they found a correlation between an individual's internet experience, the availability and access to internet facilities, and the ease in which the potential user can learn and use e-government services such as online filing. Therefore, the lack of appropriate computer literacy levels makes online tax filing expensive (Osebe, 2013).

The lack of the ability to use the e-filing system quickly and efficiently or lack of understanding of the type of information required by the online tax filing system forces taxpayers to engage the third parties (Muhangi, 2012). These third parties could be the cybercafé attendants and charge a premium for such services (Odongo, 2014). The net effect is that it becomes expensive to use online tax filing in contexts where the taxpayer is computer illiterate, hence requiring manual filing (Nakiwala, 2010). The taxpayer may also opt to execute the electronic filing on their own despite the challenges in navigating the online system (Muhangi, 2012). The difficulties in navigating the online filing system quickly and efficiently without constantly referring to the help menus or consulting third parties results in the prolonged time taken to complete the online filing (Ramoo, 2006). Therefore, the taxpayer may be burdened by the time and effort spent learning the system and hence influences the adoption of the plan (Lukwata, 2011).

\section{Perceived Security and service delivery}

Certain iTax modules are accessible only to specific security level groups. Each user belongs to a group with a particular access level with permission to view or edit different data. Each group member may only use the files or displays associated with their work and capacity (Razak, 2009). This security concept can be modified to be more refined if needed, including the possibility to write-protect or display only specific input fields, depending on the security status. A security clearance is organized according to official capacity. Managers will have reading access only; assessors will only be able to enter and edit data in their field of activity; accountants will monitor and supervise all payment activities (Lai and Choong 2010). In addition to limiting possible user actions, all user activity is tracked and logged for security audit purposes (Muhangi, 2012).

Tax rates and regulations frequently change, for example, to compensate for inflation. The iTax module is designed so that the revenue authorities can easily incorporate legal requirements without changing the program code. Additionally, the database stores the history of tax legislation. Thus, values and critical variables of new tax laws can be integrated even before the new legislation comes into effect, without interfering with previous and ongoing computation functions (Nyaga, 2015). The dependent on the third parties to assist a taxpayer in undertaking online tax returns has lost data privacy (Lai \& Choong, 2010). The taxpayer needs to reveal personal financial details about his business, such as the income derived from the company (Lukwata, 2011). A majority of the taxpayers may not be comfortable divulging such information to third parties who are not connected to their business (Ramoo, 2006). This is because it exposes them to the security risk of being robbed. In this context, the taxpayer may opt to fill the manual tax returns to protect the privacy of his data. The lack of computer literacy in general and the lack of confidence around the online filing system lead to psychological predispositions that may influence the adoption of electronic filing (Wangu 2011).

\section{Online Tax System Stability and Service Delivery}

The online tax filing system must be stable to handle the high traffic during peak times. In this context, Kamarulzaman \& Azmi (2010) argued that the online system must run smoothly and efficiently during peak times significantly closer to the deadlines. The inability of the system to handle massive information during peak hours changed the perception of the 
users, who concluded that the system was unreliable Nakiwala, (2010). Customers in this context may thus opt to utilize the manual filing due to the perception that the system is always unreliable Mugo, (2013). According to Azmi \& Bee (2010), an improvement in the e-filing systems enhanced the taxpayer's perceived ease of use, usefulness and reduced riskiness of the system was essential in adopting the e-filing system. Mugo (2013) noted that reducing taxpayer's perception of risk in electronic filing did not only increase their perception of the usefulness of the electronic filing but also led them to adopt the system.

Ramoo (2006) argued that computer anxiety affected the adoption of the electronic filing of tax returns. Computer anxiety was defined as the fear and apprehension felt by an individual when considering computer technology or when using it (Lukorito, 2012). There were two components of computer anxiety which comprised the cognitive and the dynamic components. The mental part stood for the negative expectancies and the emotional expectancy, which led to adverse physiological reactions (Pascal, 2014). Computer anxiety had been considered to impact the perceived ease of use, computer use, and computing skills, which led to the slow adoption of the electronic filing system. Computer anxiety was most likely issued among the illiterate, semi-illiterate, and the elderly taxpayers Hussein et al., (2010). Some traders had relatively low education levels, which reduced their confidence in computer technologies such as the online filing system.

\section{Critiques of the past studies}

Ibrahim (2012) argued that the online system must run smoothly and efficiently during peak times significantly closer to the deadlines. The inability of the system to handle colossal information during the peak hours changed the perception of the users, who concluded that the system was unreliable (Geetha and Sekar, 2012). Customers in this context may thus opt to utilize the manual filing due to the perception that the system is always unreliable Mugo, (2013). According to Azmi \& Bee (2010), an improvement on the e-filing systems enhanced the taxpayer's perceived ease of use, usefulness and reduced riskiness of the system was essential in adopting the e-filing system. Gitaru (2017) noted that reducing taxpayer's perception of risk in electronic filing did not only increase their perception of the usefulness of the electronic filing but also led them to adopt the system. Luchinga (2014) argued that computer anxiety affected the adoption of the electronic filing of tax returns. Computer anxiety was defined as the fear and the apprehension felt by an individual when considering the utilization of computer technology or when using it Nakiwala, (2010). There were two components of computer anxiety which comprised the cognitive and the dynamic components. The mental part stood for the negative expectancies and emotional expectancy, leading to adverse physiological reactions (Mandola, 2013). Computer anxiety had been considered to impact the perceived ease of use, computer use, and computing skills, leading to the slow adoption of the electronic filing system. The computer anxiety was most likely issued among the illiterate, semi-illiterate, and the elderly taxpayers Hussein et al., (2010). Some traders had relatively low education levels, which reduced their confidence in computer technologies such as the online filing system.

\section{METHODOLOGY}

\section{Research design}

The study was anchored on a descriptive research technique since it enables the current description of the studied phenomena. This research technique was also ideal because the researcher was interested in examining the effects of the iTax system on service delivery. The questionnaires were used to describe existing phenomena by asking individuals about their perception of the impact of the itax system on service delivery in Eldoret station. The target population of this study comprised about 151 KRA staff in the North Rift region.

\section{Sample size and sampling technique}

The sample size was determined using the following formula as used by (Jepkorir et al. 2019)

This formula was applied since it helps in sample size determination when the population is known.

$\mathrm{S}=\chi^{2} \mathrm{NP}(1-\mathrm{P}) / \mathrm{d}^{2}(\mathrm{~N}-1)+\chi^{2} \mathrm{P}(1-\mathrm{P}) \ldots \ldots \ldots . . . \mathrm{Eqn} 1$

Where;

$\mathrm{S}=$ Sample size

$\chi^{2}=$ Table value of Chi-square for 1 degree of freedom at $95 \%$ confidence level (3.841)

$\mathrm{N}=$ Population Size

$\mathrm{P}=$ population Proportion (assumed to be 0.5 since this would provide the maximum sample size)

$\mathrm{d}=$ Degree of accuracy expressed as a proportion (0.06)

Therefore;

$\mathrm{S}=3.8418 * 151 * 0.50(1-0.50) / 0.06^{2}(150-1)+3.841 * 0.50(1-$

$0.50)=37 \ldots \ldots \ldots \ldots \ldots \ldots \ldots \ldots \ldots$ Eqn 2

The study used a stratified random sampling technique to constitute the sampling unit of the study. Strata were formulated based on the KRA employees working under compliance, debt, taxpayer recruitment and registration, policy unit programs, and iTax support center of the domestic taxes department at the Eldoret KRA station. Finally, random sampling was carried out within each constituent department at the station. This technique was appropriate for the study since it was cost-effective and efficient in administration. The sampling technique gave each respondent in the strata an equal probability of being sampled. 


\section{Data collection methods}

This study used both primary and secondary data sources to generate information about the effect of the tax system on service delivery by the Kenya Revenue Authority in Eldoret Station. The primary data for this study was gathered from Eldoret KRA staff with direct interviews using semistructured research questionnaires. The research instrument was in the form of a Likert scale anchored by a five-point rating ranging from strongly disagree to agree and open-ended questions strongly. On the other hand, secondary data was obtained from relevant sources such as; KRA Annual Reports, government publications (statistical abstracts), economic surveys, online books, journals, and library resources.

\section{Research Instrument}

The study used a questionnaire as a research instrument. This is because a questionnaire is an efficient research tool that, when used, the researcher obtains personal ideas from a respondent. It had the advantage of getting standard responses to items, making it possible to compare between sets of data. It also allowed the participants to give their own opinion on the issue at stake. The questionnaire was designed to address specific objectives. It had both closed-ended and open-ended questions administered to KRA Eldoret station employees who were respondents to the study. The closed-ended items gave precise information, which minimized information bias and facilitated data analysis. This was in the form of a Likert scale anchored by a five-point rating ranging from strongly disagree, disagree, neutral, agree, and strongly agree.

\section{Data collection procedures}

This study used a personal interview survey technique. With the help of two trained enumerators, the researcher administered research questionnaires to collect information from Eldoret KRA employees. The researcher chose this technique since it helped interviewers clearly explain to respondents all the variables required for the study, assisted respondents in filling research questionnaires, enabling the researcher to obtain first-hand information, and motivated them to participate in the data collection exercise. The questionnaire for this study was divided into several sections: Section A demographic characteristics of respondent section B service delivery, Section C system security, D system record-keeping, and E iTax Technical Skills and Knowledge.

\section{Pilot study}

A pilot study was conducted on the survey questionnaire by the use of 11 KRA staff. This pre-test study was based on an open-ended format to enhance the reliability and validity of data for this study. Additionally, results from this study were used as chief arsenals for improving the structure of the final research questionnaire to capture all the relevant components and anomalies for this study. Given all these adjustments, the final questionnaire was prepared and administered to 37 respondents by the researcher with the help of two trained research enumerators.

\section{Reliability and validity tests}

The researcher used the test-retest method to ensure the reliability of the data. The research enumerators did this by issuing a questionnaire to the respondent, then collects the data and analyze. After one week, the same processes were repeated to the same respondent, collected, analyzed, and compared. The internal consistency was also tested by using Cronbach Alpha, where the equal loadings were set (Alpha's coefficient $>0.7$ ). The researcher sought expert advice and guidance to ascertain the validity of the research instruments from the supervisor and critical informants at Eldoret KRA station at different departments.

\section{Data processing and analysis}

After gathering raw data from the field, the researcher conducted data cleaning, which involved identifying incomplete or inaccurate responses and correcting to improve the answers' quality. The data was coded and entered into the computer for analysis using the Statistical Package for Social Sciences (SPSS version 23). Data were analyzed using descriptive statistics techniques such as percentages, frequencies, charts, standard deviation, among many others. The researcher analyzed the data through the use of inferential statistics and descriptive statistics. Inferential statistics for this study comprised of a multiple regression model. Descriptive statistics techniques entailed the use of frequency, standard deviation, and mean. The study adopted the multi regression model to determine the relationship between iTax systems and service delivery at KRA in Eldoret station.

The multiple regression model expanded according to the study variable was expressed as;

$Y_{i}=\beta_{0}+\beta_{1} X_{1}+\beta_{2} X_{2}+\beta_{3} X_{3}+\beta_{4} X_{4}+\varepsilon_{i} \ldots$ (Eqn 3)

Where

$Y_{i}=$ Service delivery

$X_{1}=$ iTax stability

$X_{2}=$ iTax security

$X_{3}=$ iTax record keeping

$X_{4}=$ iTax technical skills

$\beta_{0}=$ Constant

$\beta_{1-4}=$ Regression coefficients

\section{FINDINGS AND DISCUSSIONS}

Table 1: Socio-demographic characteristics of the respondents

\begin{tabular}{|c|c|c|}
\hline Description & $\begin{array}{c}\text { Frequency } \\
\text { (f) }\end{array}$ & $\begin{array}{c}\text { Percentage } \\
(\%)\end{array}$ \\
\hline Gender & 25 & 67.6 \\
Male & 12 & 32.4 \\
Female & 7 & 18.9 \\
Education level & 30 & 81.1 \\
Undergraduate & & \\
Post graduate &
\end{tabular}




\begin{tabular}{|c|c|c|}
\hline Age category & 18 & 48.6 \\
18-28 years & 8 & 21.6 \\
29-39 years & 6 & 16.2 \\
40-49 years & 5 & 13.6 \\
Over 50 years & 20 & 54.1 \\
\hline Work experience & 11 & 29.7 \\
Less than 5 years & 6 & 16.2 \\
5-10 years & \\
Over 10 years &
\end{tabular}

Source: Study data, (2018)

The study results showed that most of the respondents were male, accounting for $67.6 \%$, while females represented $32.4 \%$. The study revealed men dominated various sections at the KRA Eldoret station. However, the institution is integrating the current government regulation of one-third female representation in multiple workplaces and employment opportunities. The study results revealed that most of the respondents had a post-graduate level of education $(81.1 \%)$, and only $18.9 \%$ had attained a minimum of a bachelor's degree. The high level of education equipped the KRA employees with the required technical and professional skills in the work environment.

The study findings indicated that the majority of the respondents $(48.6 \%)$ were in the age bracket of $18-28$ years, followed by age bracket of 29-39 years (21.6\%), 30-49 years $(16.2 \%)$, and finally the respondents in the age bracket of 50 and above years (13.6\%). This result meant that the KRA Eldoret station was made up of young adults who were still energetic and innovative to help meet the institution's goals. Nevertheless, the elderly employees served critical roles of mentoring and training the junior employees for effective and efficient job operations daily. The study results indicated that the majority of the respondents $(54.1 \%)$ had work experience of fewer than five years, followed by respondents with 5-10 years $(29.7 \%)$, and lastly, respondents with over ten years of work experience $(16.2 \%)$. This showed that the KRA Eldoret station employed more staff in various sections from 2014 to date. The recruitment of more employees was due to the expansion and restructuring of KRA to improve service delivery in the North Rift region.

\begin{tabular}{|c|c|c|c|c|c|}
\hline \multicolumn{6}{|c|}{ Table 2: Time is taken to serve a taxpayer } \\
\hline Description & $\mathrm{N}$ & $\begin{array}{c}\text { Mini } \\
\text { mum }\end{array}$ & $\begin{array}{c}\text { Maxi } \\
\text { mum }\end{array}$ & $\begin{array}{c}\text { Mea } \\
\mathrm{n}\end{array}$ & $\begin{array}{c}\text { Std. } \\
\text { Deviatio } \\
\mathrm{n}\end{array}$ \\
\hline $\begin{array}{c}\text { Time taken to } \\
\text { process taxpayer's } \\
\text { inquiry }\end{array}$ & 37 & 9 & 22 & $\begin{array}{c}15.1 \\
1\end{array}$ & 3.604 \\
\hline
\end{tabular}

Source: Study data, (2018)

The study findings indicated that the meantime to serve a taxpayer was 15.11 minutes with a minimum of 9 minutes and a maximum of 22 minutes. The standard deviation of time taken to serve a taxpayer was 3.604 minutes. The implication of the finding was attributed to system hang-ups, poor network coverage, and the complexity of the client's inquiry.

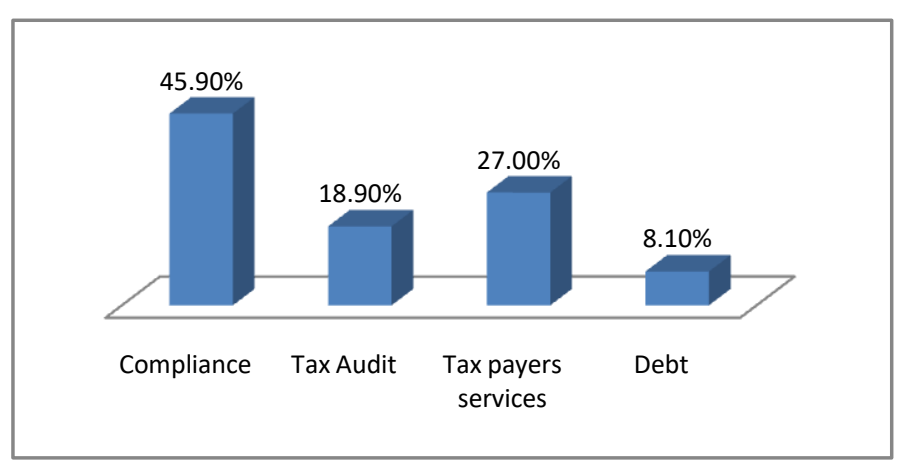

Figure 1: Respondents’ program based

Source: Study data, (2018)

The study results showed that most of the respondents $(45.9 \%)$ were based at the tax compliance section, $27 \%$ of the respondents found at the tax service section, $18.9 \%$ at the tax audit section, and $8.1 \%$ of the respondents at the debt section. The distribution of the employees was aimed at meeting the targets and enhancing service delivery in the North Rift region.

\begin{tabular}{|c|c|c|c|c|c|c|c|}
\hline \multirow{2}{*}{\multicolumn{3}{|c|}{ Model }} & \multicolumn{2}{|c|}{ Unstandardized Coefficients } & $\begin{array}{c}\text { Standardized } \\
\text { Coefficients }\end{array}$ & \multirow{2}{*}{$\mathrm{t}$} & \multirow{2}{*}{ Sig. } \\
\hline & & & B & Std. Error & Beta & & \\
\hline \multirow{5}{*}{\multicolumn{3}{|c|}{$\begin{array}{c}\text { (Constant) } \\
\text { iTax stability } \\
\text { iTax security } \\
\text { iTax record keeping } \\
\text { iTax technical skills and knowledge }\end{array}$}} & 2.386 & 1.159 & & 2.058 & .048 \\
\hline & & & .817 & .200 & .497 & 4.089 & .000 \\
\hline & & & .761 & .180 & .463 & 4.214 & .000 \\
\hline & & & .001 & .205 & .001 & .006 & .995 \\
\hline & & & .439 & .231 & .219 & 1.903 & .066 \\
\hline \multicolumn{8}{|c|}{ Model Summary } \\
\hline Model & $\mathrm{R}$ & R Square & Adjusted R Sc & \multicolumn{3}{|c|}{ Std. Error of the Estimate } & \\
\hline 1 & $.809^{\mathrm{a}}$ & .655 & .611 & \multicolumn{3}{|c|}{1.428} & \\
\hline
\end{tabular}

Source: Study data, (2018) 
The multiple regression results of the study showed that iTax stability was statistically significant at a $1 \%$ level of significance with a ( $\mathrm{p}$-value $=0.000$ ) and a positive slope (.817). The implication was that service delivery at KRA improved with the stable iTax system. The problems associated with fluctuating internet connection and system hang-up led to reduced service delivery since the taxpayers had to wait in line for a long time before being served. Mandola (2013) and Karingi et al. (2014) obtained a similar result. They revealed both a positive and significant relationship between tax stability and service delivery. Concerning iTax security, the study found a significant association with service delivery at a $1 \%$ level of significance (p-value $=0.000)$ and a positive slope (.761). This finding implied that a strong iTax security resulted in better service delivery at the KRA Eldoret station. A more secure tax system served a pertinent role in service delivery. Some taxpayers fear that their tax history may be exposed to their competitors or fraudulent when the itax system is not well secured. Osebe (2013) also found that itax security had a positive and significant association with Tax compliance among the real estate owners in Nakuru County.

Based on iTax technical skills and knowledge variable, the study results showed a significant relationship with service delivery at $10 \%$ level of significance. The variable iTax technical skills and knowledge also had a positive slope (.439) with a ( $\mathrm{p}$-value $=.066)$. This finding pointed out that staff with specialized skills and expertise on iTax systems improved the service delivery at the KRA Eldoret station. The employees with relevant technical skills and experience in ICT and iTax systems were able to service many taxpayers and even keep feedback to all queries concerning tax compliance, among other itax system operations and services offered at the KRA offices. Similar iTax system studies with similar results comprised the study by Auyat (2013); Mugo, (2013) and Geetha, and Sekar (2012). However, the variable iTax recordkeeping was not significant but positively associated with service delivery at the KRA Eldoret station.

\section{CONCLUSION}

The main goal of this study was to examine the effect of itax systems on service delivery by Kenya Revenue Authority in Eldoret station. The study specifically determined the influence of iTax security; iTax records keeping, iTax knowledge, and iTax stability on service delivery by Kenya Revenue Authority in Eldoret station. The study results showed that three were statistically significant with positive coefficients out of the four hypothesized variables. These variables comprised lax security, iTax stability, and iTax skills and knowledge. The study, therefore, concluded that iTax systems affect service delivery at KRA in Eldoret station. This was due to a robust statistical association between the iTax systems and service delivery. However, the variable iTax record-keeping was not statistically significant but positively associated with service delivery at the KRA Eldoret station.
The Kenya Revenue Authority should put tight policy measures to curb the issues associated with iTax insecurity. This will enable the taxpayers to have strong confidence when providing their confidential details to the Kenya Revenue Authority staff. The Kenya Revenue Authority should ensure the stability of the iTax system by using alternative mechanisms during system hang-ups and internet failures. The initiative will improve service delivery by reducing waiting time in the queue and efficiency in the routine operations at the Kenya Revenue Authority stations. The Kenya Revenue Authority should also employ staff with technical knowledge and skills on the iTax system. The KRA should also provide in-service training workshops to allow the on-job team to get acquainted with the new iTax systems.

\section{REFERENCES}

[1] Addison, T., \& Levin, J. (2014). The determinants of tax revenue in sub-Saharan Africa. International Journal of Economics and Finance, 6(10), 97-121.

[2] Auyat, M. (2013). E Tax Service System and Its Adoption at Uganda Revenue Authority. Interdisciplinary Journal of Contemporary Research in Business, 2(4), 36-39.

[3] Azmi, A., \& Bee, N. (2011). The Acceptance of the e-Filing System by Malaysian Taxpayers : A Simplified Model. Electronic Journal of E-Government, 8(1), 13-22.

[4] Azmi, A., Sapiei, N. S., Mustapha, M. Z., \& Abdullah, M. (2016). SMEs' tax compliance costs and IT adoption: the case of a valueadded tax. International Journal of Accounting Information Systems, 23, 1-13.

[5] Davidson, P. (2015). Post Keynesian theory and policy: A realistic analysis of the market oriented capitalist economy. NY: Edward Elgar Publishing.

[6] Geetha, R., \& Sekar, M. (2012). E-Filing of Income Tax : Awareness and Satisfaction level of individual Tax payers in Coimbatore city, India. Research Journal of Management Sciences, 1(4), 6-11.

[7] Gitaru, K., (2017). The Impact of System Automation on revenue collection in Kenya (A case study of Simba). The University of Nairobi, Kenya

[8] Hussein, R., Mohamed, N., Ahlan, A. R., Mahmud, M., \& Aditiawarman, U. (2010). An Integrated Model on Online Tax Adoption in Malaysia. International Journal of Asian Social Science, 3(2), 1-16.

[9] Ibrahim, I. (2012). Factors Underpinning Usage Behaviour of an Electronic Filing System: The Case of Malaysian Personal Taxpayers. International Journal of Asian Social Science, 4(3), 121.

[10] Jepkorir C.B., Otieno S.J., Dr. WakhuWamunga F., and Dr. Serem D., (2019). "Prevalence of Under-Nutrition and Food Security among the Elderly in Uasin Gishu County, Kenya" IOSR Journal Of Humanities And Social Science (IOSR-JHSS) Volume 24, Issue 7, Ser. 4 (July. 2019) 29-34 e-ISSN: 2279-0837, p-ISSN: 2279 0845. DOI: 10.9790/0837-2407042934. Available online at http://iosrjournals.org/iosr-jhss/pages/24(7)Series-4.html

[11] Kamarulzaman, Y., \& Azmi, A. A. C. (2010). Tax E-filing Adoption in Malaysia : A Conceptual Model. Journal of Accounting and Finance, 3(4), 25-29.

[12] Kenya Revenue Authority (2012): “Annual Revenue Performance Report FY 2004/05,” KRA, Eldoret, Kenya.

[13] Kenya Revenue Authority (2015): "Annual Revenue Performance Report FY 2014/15,” KRA, Eldoret, Kenya.

[14] Kiring'a, S.E and Jagomgo A., (2017). Impact of online tax compliance among small and medium enterprises (SME) in Kibwezi Sub County in Kenya, International Journal of Current Research, 9(10), 451966-45206.

[15] Korir, J., Adoyo, P., Isaac, N. Aila, F.O., Asewe., and Momanyi, G. (2015). Determinance of tax compliance among small tax 
payers in western Kenya, Greener Journal of Economics and Accountancy, 4(1), 9-20.

[16] Lai, M., \& Choong, K. (2010). Motivators, Barriers and Concerns in Adoption of Electronic Filing System: Survey Evidence from Malaysian Professional Accountants. American Journal of Applied Sciences, 3(4), 10-15.

[17] Luchinga, L. (2014). The Effect of Working Capital Management on the Profitability of Agricultural Firms Listed in Nairobi Securities Exchange. Journal of Business and Management, 2(1), $37-45$.

[18] Lukorito, G. M. (2012). Information Security Threats and EGovernment Initiatives at the Kenya Revenue Authority (KRA). International Journal of Business, Humanities and Technology, 2(2), 7-9.

[19] Lukwata, H. (2011). The Influence of Electronic Tax Filing System and Tax Compliance and Tax Collection. International Journal of Business and Management Invention, 3(2), 5-7.

[20] Mandola, V. (2013). Factors Influencing the Adoption and Use of Integrated Tax Management System by Medium and Small Taxpayers in Nairobi Central Business District, Kenya. Interdisciplinary Journal of Contemporary Research in Business, 2(2), 12-15.

[21] Mugo, F. (2013). The Effect of Electronic Tax Registers on Value Added Tax Administration in Kenya: A Case Study of Hotels in Nairobi County. Journal of Accounting and Finance, 3(4), 15-17.

[22] Muhangi, D. (2012). Taxation and Growth of Small Scale Business Enterprises in Uganda: A Case Study of Kikuubo Market, Central Division in Kampala District. International Journal of Business and Management Invention, 2(3), 45-47.

[23] Nakiwala, A. (2010). Tax Competencies, Compliance Costs and Income Tax Compliance Among SMEs in Uganda. International Journal of Business and Public Management, 1(2), 25-27.

[24] Nyaga, K. (2015). The impact of Mobile Money Services on the performance of Small and Medium Enterprises in an urban town in Kenya. International Journal of Business and Management Invention, 3(2), 23-24.
[25] Odongo, B. (2014). Impact of Taxes on Performance of Small Scale Business Enterprises in Ntungamo Town Council. Journal of Economics and International Business Research, 3(4), 25-27.

[26] OECD Employment Outlook, (2012). SMEs: Employment, Innovation and Growth - The Washington Workshop, Paris.

[27] Osebe, R. (2013). An Analysis of Factors Affecting Tax Compliance in the Real Estate Sector in Kenya: A Case Study of Real Estate Owners in Nakuru Town. Journal of Emerging Issues in Economics, Finance and Banking (JEIEFB), 1(4), 7-9.

[28] Pascal, P. A., (2014). Presence of Transnational Corporations in Africa: An Assessment of Tax Justice and Poverty Implications in the Light of Catholic Social Teaching.

[29] Ramoo, V. (2006). Determinants of Perceived Ease of Use of EFiling. Journal of Emerging Issues in Economics, Finance and Banking (JEIEFB), 3(1), 17-20.

[30] Razak, M. (2009). Taxpayers' Attitude In Using E-Filing System: Is There Any Significant Difference Among Demographic Factors? Journal of Internet Banking and Commerce, 14(1), 1-13.

[31] Roger, G., (2010). Taxation in Developing Countries: Six Case Studies and Policy Implications

[32] Simiyu, D. (2013). Challenges Affecting Collection of Turnover Tax in Nairobi County-Kenya. International Journal of Business and Social Research, 3(4), 25-27.

[33] Van Parys, S., \& James, S. (2010). The effectiveness of tax incentives in attracting investment: panel data evidence from the CFA Franc zone. International Tax and Public Finance, 17(4), 400-429.

[34] Veras, J., \& Preziosi, M., (2011). Behavioural investigation on the factors that determine adoption of an electronic toll collection system: Passenger car users. Transportation Research Part C: Emerging Technologies, 19(3), 498-509.

[35] Wangu, M. P. (2011). Access to itax services and Performance of Small and Medium Enterprises. International Journal of Business and Public Management, 4(2), 17-19. 